\title{
Polymorphisms in interleukin 17A gene and coal workers' pneumoconiosis risk in a Chinese population
}

\author{
Ruhui Han ${ }^{1 \dagger}$, Xiaoming $\mathrm{ji}^{1 \dagger}$, Baiqun $\mathrm{Wu}^{1 \dagger}$, Ting Wang ${ }^{1}$, Lei Han ${ }^{1}$, Jingjin Yang ${ }^{1}$, Baoli Zhu ${ }^{2}$ and Chunhui $\mathrm{Ni}^{1 *}$
}

\begin{abstract}
Background: The interleukin 17A (IL-17A) which is located on chromosome $6 \mathrm{p}$ and has been linked to chronic inflammation, is an important candidate gene conferring coal workers' pneumoconiosis (CWP). The purpose of this study was to investigate the genetic association between single nucleotide polymorphisms (SNPS) of IL-17A and CWP in a Chinese population.
\end{abstract}

Methods: We conducted a case-control study to investigate the role of four common SNPs in the IL-17A gene, and evaluated the relationship between these four SNPs and dust-exposure year, tobacco smoking and stages of CWP. A total of 1391 subjects was enrolled in this study, including 694 subjects in control group and 697 in case group. TaqMan based qRT-PCRs were taken to genotype rs2275913, rs3748067, rs4711998, and rs8193036 within the IL-17A gene. Luciferase assays were used to determine the effects of rs8193036 C > T alleles on the expression of IL-17A.

Results: Unconditional logistic regression analysis showed that the genotypes of rs3748067 AA (adjusted OR $=0.43$, $95 \% \mathrm{Cl}=0.23-0.83$ ) and $\mathrm{rs} 8193036 \pi$ (adjusted $\mathrm{OR}=0.59,95 \% \mathrm{Cl}=0.40-0.86$ ) were associated with a decreased risk of CWP, particularly among subgroups of smokers (adjusted $\mathrm{OR}=0.34,95 \% \mathrm{Cl}=0.13-0.86$ for rs3748076; adjusted $\mathrm{OR}=0.41,95 \% \mathrm{Cl}=0.23-0.71$ for 8193036) and CWP cases with stage I (adjusted $\mathrm{OR}=0.45,95 \% \mathrm{Cl}=0.21-0.98$ for rs3748076; adjusted $\mathrm{OR}=0.46,95 \% \mathrm{Cl}=0.28-0.74$ for 8193036). Furthermore, the polymorphism of rs3748067 significantly reduced the CWP risk among cases with over 27 years of dust exposure (adjusted OR=0.42, $95 \%$ $\mathrm{Cl}=0.18-0.97)$. The luciferase assays in two cell lines showed that the rs8193036 C > T substitution could reduce the expression of IL-17A, which was consistent with the findings of our association study.

Conclusions: The rs3748067 G > A and rs8193036 C > T polymorphisms decrease CWP risk. These findings could be helpful in identifying individuals at decreased risk for CWP and further studies are warranted to validate them.

Keywords: Genetics, IL-17A, Polymorphisms, Coal workers' pneumoconiosis

\section{Background}

Coal workers' pneumoconiosis (CWP), common occurred in underground coal miners, is one of the most prevalent occupational diseases in China. CWP is characterized by chronic lung inflammation and formation of fibrotic nodular lesions that results from the inhalation of airborne coal mining dust which usually contains free crystalline silica $[1,2]$. CWP is a kind of progressive and irreversible fibrotic lung diseases without any effective

\footnotetext{
*Correspondence: chninjmu@126.com

${ }^{\dagger}$ Equal contributors

'Department of Occupational Medicine and Environmental Health, School of Public Health, Nanjing Medical University, Nanjing 210029, China

Full list of author information is available at the end of the article
}

therapy. It was reported that cytokines, such as transforming growth factor- $\beta 1$ (TGF- $\beta 1$ ), interleukin (IL)- $1 \beta$, IL- 6 and IL-13, were produced by alveolar macrophages to promote lung inflammation after silica inhalation. Persistent inflammation was converted into lung fibrosis eventually [3, 4]. Many factors are related to the prevalence of CWP, including the long time exposure to high concentrations of respirable crystalline silica $[5,6]$, poor personal protection and individual susceptibility [7].

Interleukin-17A $(I L-17 A)$ is a cytokine with strong pro-inflammatory effect and has been reported to be elevated in fibrotic disorders $[8,9]$. $I L-17 A$ is important for host defense against extracellular pathogens and it can 
lead to drastic inflammatory responses by recruiting neutrophils and other cytokines [10]. Thus, $I L-17 A$ may play a crucial role in the inflammation of silicosis [11]. $I L-17 A$ is produced by a subset of CD4+ T-helper (Th) cells, Th17 cells, which are distinct from the classic Th1 and Th2 cells. Therefore, $I L-17 A$ plays an important role in both innate and adaptive immunities [12, 13]. However, $I L-17 A$ is secreted not only by Th17 cells, but by $\gamma \delta$ T-cells and natural killer T-cells as well $[14,15]$. Previous studies about $I L-17 A$ in CWP were rare whereas the effect of $I L-17 A$ in lung inflammation and fibrosis was definite. Increased levels of $I L-17 A$ have been demonstrated in bronchoalveolar lavage (BAL) of patients with IPF and lung tissues exposed to BLM and IL-1 $\beta$ [16]. Neutralization of $I L-17 A$ could delay the progression of silica-induced lung inflammation and fibrosis in C57BL/6 mice $[17,18]$. A huge number of studies have identified the association between the IL-17A polymorphisms and risk for human disorders, such as pediatric asthma [19], multiple sclerosis [20], gastric cancer [21], and dilated cardiomyopathy [22]. In the present study, we attempted to clarify the association between $I L-17 \mathrm{~A}$ polymorphisms and CWP risk in a Chinese population.

\section{Materials and methods \\ Study population}

Our study population consisted of 697 CWP patients and 694 controls. They were recruited from the coal mines of Xuzhou Mining Business Group Co., Ltd. between January 2006 and December 2010, as described previously [23]. Briefly, all participants were genetically unrelated Chinese Han males and were underground coal miners who spent their entire working career within the above mentioned company. The subjects with clinical evidence of autoimmunity diseases, had received immunosuppressive or immunostimulatory therapy, or were subjected to radiotherapy were excluded. High kilovolt chest X-ray and physical examinations were performed based on the China National Diagnostic Criteria for Pneumoconiosis (GBZ 70-2002), which are the same as that of the 1980 International Labour Organization (ILO) in the judgment of opacity profusion,to reconfirm the diagnoses [24] . According to the size, profusion, and distribution of opacities, all patients were classified into stage I, stage II or stage III. The chest X-rays were assessed by at least two independent physicians. The questionnaire for each participant was conducted by the face-to-face interview using a double-blind method. This epidemiological questionnaire focused on age, respiratory symptoms, occupational histories, and smoking habits and some others. Blood sample of $5 \mathrm{ml}$ was obtained from each participant, and was used for routine lab tests. The control subjects were miners matched with the CWP cases for age, dust exposure period, and job types from the same company in order to make the dust exposure histories between cases and controls were comparable. This study protocol was specifically approved by the Institutional Review Board of Nanjing Medical University and all subjects gave their written informed consent before participating in the study.

\section{Genotyping}

Conventional phenol-chloroform method was used to extract the genomic DNA from peripheral blood lymphocytes. Genotyping was performed using the TaqMan method with the ABI 7900HT Real Time PCR system according to the manufacturer's instructions (Applied Biosystem, Foster city, CA, USA) in a blinded fashion, which means the people conducted the genotyping experiment was unaware of the workers' personal details or case status. The sequences of primer and probe for each SNP are available on request. Genomic DNA (50 ng) was used for each reaction, and amplification was performed under the following conditions: $50{ }^{\circ} \mathrm{C}$ for $2 \mathrm{~min}$ and $95^{\circ} \mathrm{C}$ for $10 \mathrm{~min}$ followed by 45 cycles of $95^{\circ}$ $\mathrm{C}$ for $15 \mathrm{sec}$ and $60{ }^{\circ} \mathrm{C}$ for $1 \mathrm{~min}$. Negative controls were included in each plate to ensure accuracy of the genotyping. $10 \%$ of the samples were randomly selected for confirmation, and the results were $100 \%$ concordant.

\section{Cell culture}

Human lung adenocarcinoma A549 cells and human bronchial epithelial (HBE) cells were purchased from the Shanghai Institute of Biochemistry and Cell Biology, Chinese Academy of Science (Shanghai, China). Cells were cultured in Dulbecco modified Eagle medium supplemented with $100 \mathrm{U} / \mathrm{ml}$ penicillin, $100 \mu \mathrm{g} / \mathrm{ml}$ streptomycin, and $10 \%$ fetal bovine serum. The cells were grown at $37{ }^{\circ} \mathrm{C}$ in the presence of $5 \%$ carbon dioxide in a humidified incubator.

\section{Construction of luciferase reporter plasmids}

We constructed 2 luciferase reporter plasmids to explore whether rs8193036C $>\mathrm{T}$ polymorphism had an effect on IL-17A gene expression in vitro. The constructs of a 792bp DNA fragment corresponding to the upstream region of the transcription start site of $I L-17 A$, which were amplified from individual homozygous templates and were cloned into the pGL3-basic luciferase vector (Promega, Madision, WI). The vectors were then sequenced to confirm that there were no nucleotide errors.

\section{Transient transfections and luciferase assays}

A549 and HBE cells were seeded in 24-well plates, and each well was transfected with $2.4 \mu \mathrm{g}$ of the vector DNA containing either $\mathrm{C}$ or $\mathrm{T}$ allele of rs8193036 and $0.08 \mu \mathrm{g}$ of pRL-SV40 which contains the Renilla luciferase gene by Lipofectamine 2000 (Invitrogen, Carlsbad, CA), according to the manufacture's instruction. Cells were collected $48 \mathrm{~h}$ 
after transfection, and luciferase activity was measured with a dual Luciferase reporter assay system (Promega) and was normalized against the activity of the Renilla luciferase gene. Independent triplicate experiments were performed for each plasmid.

\section{Statistical analyses}

Differences in the distributions of demographic characteristics, selected variables, and frequencies of genotypes of $I L-17 A$ polymorphisms between the CWP cases and controls were evaluated by using the Student's $t$-test or $\chi^{2}$-test. The Hardy-Weinberg equilibrium (HWE) was tested using a goodness-of-fit $\chi^{2}$-test. The associations between genotypes and CWP were estimated by computing odds ratios (ORs) and their $95 \%$ confidence intervals (CIs) from unconditional logistic regression analysis with the adjustment for possible confounders.

The statistical power was calculated by using the PS software (http://biostat.mc.vanderbilt.edu/twiki/bin/view/ Main/PowerSampleSize). For the stratified analysis, the age and dust-exposure cutoff was according to the median of age and dust-exposure years of the participants. All statistical tests were two-sided at a significance level of 0.05 and were analyzed by the SAS software (version 9.1; SAS Institute, Inc., Cary, NC).

\section{Results}

Four IL-17A SNPs were genotyped in 697 CWP patients and 693 controls. The information about frequency distributions of the selected characteristics was summarized in Table 1 . There were no significant difference between the cases and controls in the distribution of age $(P=0.103)$, exposure years $(P=0.105)$, and job types $(P=0.534)$. Although the smoking status of CWP was similar to the controls $(P=0.250)$, the smoking amount (pack-years) in CWP cases was significantly less than that of controls $(P<0.001)$. The frequency distributions and means of the selected characteristics were matched adequately between cases and controls. Furthermore, of the 697 CWP cases, the pneumoconiosis stages from I to III were 415 (59.5\%), $219(31.4 \%)$ and 63 (9.0\%).

The primary information and allele frequencies observed were listed in Table 2. All genotyped distributions of control subjects were consistent with those expected from the Hardy-Weinberg equilibrium. The minor allele frequencies (MAF) of these four polymorphisms were consistent with that reported in the HapMap database (http://www.hapmap.org).

Logistic regression analysis was performed to assess the effect of each SNP on CWP risk (adjusting for age, exposure years, job type, and pack-years of smoking). Parameters for the association of SNPs with CWP were

Table 1 Demographic and selected variables among the CWP cases and controls

\begin{tabular}{|c|c|c|c|c|c|}
\hline \multirow[t]{2}{*}{ Variables } & \multicolumn{2}{|c|}{$\operatorname{CWP}(n=697)$} & \multicolumn{2}{|c|}{ Controls $(n=694)$} & \multirow[t]{2}{*}{$P$} \\
\hline & Number & Percent & Number & Percent & \\
\hline Age, year (mean $\pm S D)$ & $68.0 \pm 11.1$ & & $67.1 \pm 8.4$ & & 0.103 \\
\hline Exposure years (mean $\pm S D$ ) & $26.6 \pm 9.0$ & & $27.3 \pm 7.8$ & & 0.105 \\
\hline \multicolumn{6}{|l|}{ Smoking status } \\
\hline Never & 340 & 48.8 & 360 & 51.9 & 0.250 \\
\hline Ever & 357 & 51.2 & 334 & 48.1 & \\
\hline Former & 163 & 23.4 & 91 & 13.1 & \\
\hline Current & 194 & 27.8 & 243 & 35.0 & \\
\hline Pack-years smoked & & & & & $<0.001$ \\
\hline 0 & 340 & 49.2 & 360 & 52.6 & \\
\hline $0-20$ & 223 & 32.0 & 132 & 19.0 & \\
\hline$>20$ & 134 & 19.2 & 202 & 29.1 & \\
\hline Work type & & & & & 0.534 \\
\hline Tunnel and coal mining & 663 & 95.1 & 652 & 94.0 & \\
\hline Transport & 16 & 2.3 & 17 & 2.5 & \\
\hline Others & 18 & 2.6 & 25 & 3.6 & \\
\hline \multicolumn{6}{|l|}{ Stage } \\
\hline I & 415 & 59.5 & & & \\
\hline$\|$ & 219 & 31.4 & & & \\
\hline III & 63 & 9.0 & & & \\
\hline
\end{tabular}


Table 2 Primary information of genotyped SNPs in IL-17(IL-17 polymorphisms)

\begin{tabular}{llllll}
\hline rs no. & Location & $\begin{array}{l}\text { Base } \\
\text { change }\end{array}$ & $\begin{array}{l}\text { MAF } \\
\text { Case }\end{array}$ & Control & HWE $^{a}$ \\
\hline rs2275913 & 5'UTR & G > A & 0.440 & 0.435 & 0.393 \\
rs3748067 & 3'UTR & G > A & 0.160 & 0.189 & 0.135 \\
rs4711998 & 5'UTR & A > G & 0.284 & 0.285 & 0.852 \\
rs8193036 & 5'UTR & C > T & 0.289 & 0.333 & 0.493 \\
\hline
\end{tabular}

${ }^{\mathrm{a} H W E} P$ value in the control group

shown in Table 3. The analysis revealed that two SNPs (rs3748067, rs8193036) of $I L-17 A$ were associated with the risk of CWP significantly. It was revealed that the variant allele decreased the susceptibility to CWP under co-dominant $(\mathrm{OR}=0.43,95 \% \mathrm{CI}=0.22-0.81, P=0.010$ for $\mathrm{AA}$ versus $\mathrm{GG}$ for $\mathrm{rs} 3748067$; $\mathrm{OR}=0.60,95 \% \mathrm{CI}=$ $0.41-0.87, P=0.007$ for TT versus $C C$ for rs8193036), recessive $(\mathrm{OR}=0.44,95 \% \mathrm{CI}=0.23-0.83, P=0.012$ for rs3748067; OR $=0.64,95 \% \mathrm{CI}=0.44-0.91, P=0.014$ for rs8193036), and additive $(\mathrm{OR}=0.82,95 \% \mathrm{CI}=0.67-0.99$, $P=0.012$ for $r s 3748067$; $\mathrm{OR}=0.81,95 \% \mathrm{CI}=0.69-0.95$, $P=0.011$ for rs8193036) models. These associations remained significant after adjusting for age, exposure years, and pack-years smoking. Carrying the A allele of rs3748067 was associated with decreased risk (adjusted $\mathrm{OR}=0.81,95 \% \mathrm{CI}=0.66-0.99)$. Similarly, subjects with the $I L-17 A$ rs8193036 T allele showed a lower decreased risk relative to the $\mathrm{C}$ allele, with adjusted $\mathrm{OR}=0.80,95 \%$ $\mathrm{CI}=0.68-0.95$, respectively. However, no association was found between rs2275913 G > A, rs4711098 A > G polymorphism and CWP occurrence.

We further investigated the effect of exposure years, smoking status and stage of CWP on the association between $I L-17 A$ gene polymorphisms and CWP risk. As shown in Table 4, the association between rs3748067 and CWP risk remained significant among subjects who had longer than 27 years of exposure $(\mathrm{OR}=0.42,95 \% \mathrm{CI}$ $=0.18-0.97, P=0.041)$ under a recessive model. However, the variants rs8193036 significantly decreased CWP risk of individuals who had less than 27 years of exposure ( $\mathrm{OR}=0.46,95 \% \mathrm{CI}=0.25-0.85, P=0.014)$ under a recessive model (Table 5). In addition, the variants rs3748067 and rs8193036 both significantly decreased CWP risk of smokers $(\mathrm{OR}=0.34,95 \% \mathrm{CI}=0.13-0.86, P=0.022$ for rs3748067; $\mathrm{OR}=0.41,95 \% \mathrm{CI}=0.23-0.71, P=0.002$ for rs8193036) under a recessive model. Additionally, significant associations were observed between the genotypes and patients with stage $\mathrm{I}(\mathrm{OR}=0.45,95 \% \mathrm{CI}=0.21-0.98$, $P=0.045$ for $\mathrm{rs} 3748067$; OR $=0.46,95 \% \mathrm{CI}=0.28-0.75$, $P=0.001$ for rs8193036) under a recessive model. Furthermore, case-control logistic regression analysis was conducted to investigate the interaction between SNP and smoking status. Nevertheless, no variants was interacted with smoking status significantly $(\mathrm{OR}=0.71$, $95 \% \mathrm{CI}=0.20-2.56, P=0.596$ for $\mathrm{rs} 3748067$; $\mathrm{OR}=0.60$, $95 \% \mathrm{CI}=0.29-1.24, P=0.163$ for rs8193036; Table 6).

In order to evaluate whether the $I L-17 A$ rs8193036 $\mathrm{C}>\mathrm{T}$ polymorphism is associated with the transcriptional activity of $I L-17 A$, pGL3-basic vectors with either rs8193036 C or rs8193036 T allele were constructed. The above vectors were transfected into A549 or HBE cells, respectively. As shown in Fig. 1, the vectors with rs8193036 $\mathrm{T}$ allele reduced the relative luciferase activities significantly, compared with the rs8193036 C allele in both of the cell lines $(P<0.05)$. These results suggested that the rs8193036 T allele in the 5'UTR region was associated with a decreased transcriptional activity of $I L-17 A$.

\section{Discussion}

This study was investigated to explore the probable relationship between $I L-17 A$ genetic variants and the susceptibility to CWP. We found a remarkable association between two SNPs (rs3748067 and rs8193036) of $I L-17 A$ gene and the resistance to the disease, and the associations were more evident in smokers. Similarly, subjects carrying the rs3748067 AA and rs8193036 TT genotypes had a moderately decreased risk of CWP patients with stage I. Luciferase assays demonstrated that IL-17A promoters with rs8193036 $\mathrm{T}$ allele decreased the transcriptional activity of $I L-17 A$, compare with rs8193036 C allele, which was consistent with the findings in our relevant study.

CWP is a serious occupational disease which is common occurred in underground coal miners. There is no effective treatment for CWP currently. The incidence and progression of CWP are determined by both dust exposure levels [5] and silica content in the dust [24]. However, only few people exposed to coal dust or silica developed CWP ultimately. Thus, characterization and identification of genes involved in the genetic predisposition or progression have an important role in clinical settings for the treatment of CWP [25].

IL-17 is a cytokine released from Th17 and other IL17 producing cells, IL-17 cytokine family consists of six members including $I L-17 A$ (IL-17), IL-17B, IL-17C, IL$17 D, I L-17 E$ (also known as $I L-25$ ) and $I L-17 F$. Many cells are $I L-17 A$-responsive, such as epithelial cells, endothelial cells, fibroblasts, macrophages, and dendritic cells. Furthermore, Th17 cell and other cells which as producers of $I L-17 A$ are also sensitive to the cytokine [26]. $I L-17 A$ plays a crucial role in the development and progression of both acute and chronic inflammationinduced pulmonary fibrosis. It may modulate the inflammatory response and synthesis of collagen [17, 27]. In addition, the elevated expression of $I L-17 A$ has been 
Table 3 Distributions of genotypes of $1 L-17$ and their associations with risk of CWP

\begin{tabular}{|c|c|c|c|c|c|c|c|c|}
\hline \multirow[t]{2}{*}{ Variables } & \multicolumn{2}{|c|}{ CWP cases } & \multicolumn{2}{|l|}{ Controls } & \multirow[t]{2}{*}{$P^{a}$} & \multirow[t]{2}{*}{ OR (95\% Cl) } & \multirow[t]{2}{*}{$P^{b}$} & \multirow[t]{2}{*}{ OR $(95 \% C l)^{b}$} \\
\hline & Number & Percent & Number & Percent & & & & \\
\hline rs2275913 & $n=692$ & & $n=687$ & & & & & \\
\hline GG & 221 & 31.9 & 225 & 32.8 & & 1.00 & & 1.00 \\
\hline$A G$ & 333 & 48.1 & 326 & 47.5 & 0.749 & $1.04(0.82-1.32)$ & 0.665 & $1.05(0.83-1.34)$ \\
\hline AA & 138 & 19.9 & 136 & 19.8 & 0.832 & $1.03(0.76-1.40)$ & 0.734 & $1.05(0.78-1.43)$ \\
\hline G allele & 775 & 56.0 & 776 & 56.5 & & 1.00 & & 1.00 \\
\hline A allele & 609 & 44.0 & 598 & 43.5 & 0.800 & $1.02(0.88-1.19)$ & 0.695 & $1.03(0.89-1.20)$ \\
\hline ADD & & & & & 0.802 & $1.02(0.88-1.18)$ & 0.699 & $1.03(0.88-1.20)$ \\
\hline DOM & & & & & 0.746 & $1.03(0.83-1.30)$ & 0.647 & $1.05(0.84-1.32)$ \\
\hline REC & & & & & 0.946 & $1.01(0.77-1.32)$ & 0.880 & $1.02(0.78-1.33)$ \\
\hline rs3748067 & $n=693$ & & $n=690$ & & & & & \\
\hline GG & 486 & 70.1 & 460 & 66.7 & & 1.00 & & 1.00 \\
\hline GA & 193 & 27.8 & 199 & 28.8 & 0.476 & $0.92(0.73-1.16)$ & 0.408 & $0.90(0.71-1.15)$ \\
\hline AA & 14 & 2.0 & 31 & 4.5 & 0.010 & $0.43(0.22-0.81)$ & 0.011 & $0.43(0.23-0.83)$ \\
\hline G allele & 1165 & 84.1 & 1119 & 81.1 & & 1.00 & & 1.00 \\
\hline A allele & 221 & 15.9 & 261 & 18.9 & 0.040 & $0.81(0.67-0.99)$ & 0.035 & $0.81(0.66-0.99)$ \\
\hline ADD & & & & & 0.041 & $0.82(0.67-0.99)$ & 0.036 & $0.81(0.67-0.99)$ \\
\hline DOM & & & & & 0.166 & $0.85(0.68-1.07)$ & 0.139 & $0.84(0.67-1.06)$ \\
\hline REC & & & & & 0.012 & $0.44(0.23-0.83)$ & 0.014 & $0.44(0.23-0.85)$ \\
\hline rs4711998 & $n=693$ & & $n=689$ & & & & & \\
\hline AA & 350 & 50.5 & 353 & 51.2 & & 1.00 & & 1.00 \\
\hline GA & 293 & 42.3 & 279 & 40.5 & 0.610 & $1.06(0.85-1.31)$ & 0.558 & $1.06(0.86-1.33)$ \\
\hline GG & 50 & 7.2 & 57 & 8.3 & 0.556 & $0.88(0.59-1.33)$ & 0.628 & $0.90(0.60-1.36)$ \\
\hline A allele & 993 & 71.6 & 985 & 71.5 & & 1.00 & & 1.00 \\
\hline G allele & 393 & 28.4 & 393 & 28.5 & 0.924 & $0.99(0.84-1.17)$ & 0.984 & $1.00(0.85-1.18)$ \\
\hline ADD & & & & & 0.923 & $0.99(0.84-1.17)$ & 0.984 & $1.00(0.85-1.18)$ \\
\hline DOM & & & & & 0.787 & $1.03(0.83-1.27)$ & 0.711 & $1.04(0.84-1.29)$ \\
\hline REC & & & & & 0.462 & $0.86(0.58-1.28)$ & 0.518 & $0.88(0.59-1.31)$ \\
\hline rs8193036 & $n=693$ & & $n=690$ & & & & & \\
\hline CC & 347 & 50.1 & 311 & 45.1 & & 1.00 & & 1.00 \\
\hline TC & 292 & 42.1 & 298 & 43.2 & 0.252 & $0.88(0.70-1.10)$ & 0.233 & $0.87(0.70-1.09)$ \\
\hline$\pi$ & 54 & 7.8 & 81 & 11.7 & 0.007 & $0.60(0.41-0.87)$ & 0.006 & $0.59(0.40-0.86)$ \\
\hline C allele & 986 & 71.1 & 920 & 66.7 & & 1.00 & & \\
\hline T allele & 400 & 28.9 & 460 & 33.3 & 0.011 & $0.81(0.69-0.95)$ & 0.009 & $0.80(0.68-0.95)$ \\
\hline ADD & & & & & 0.011 & $0.81(0.69-0.95)$ & 0.009 & $0.81(0.69-0.95)$ \\
\hline DOM & & & & & 0.062 & $0.82(0.66-1.01)$ & 0.053 & $0.81(0.66-1.00)$ \\
\hline REC & & & & & 0.014 & $0.64(0.44-0.91)$ & 0.011 & $0.63(0.43-0.90)$ \\
\hline
\end{tabular}

$A D D$ wild homozygote versus heterozygote versus mutational homozygote, DOM wild homozygote versus heterozygote and mutational homozygote, REC wild homozygote and heterozygote versus mutational homozygote

${ }^{\mathrm{a}}$ Two-sided $x^{2}$ test

${ }^{\mathrm{b}}$ Adjusted for age, exposure years, jobtype, and pack-years of smoking in logistic regression model

reported in animal models of fibrotic disease and in human fibrotic tissues, including lungs [28], livers [29], skin [9] and others.

IL-17A participates in the pathogenesis of fibrotic disorders maybe through three pathways. First, $I L-17 A$ can regulate lung inflammation through an IL-1 $\beta$ dependent mechanism [9]. A previous study has described that innate $I L-1 \beta-I L-23-I L-17 A$ axis in the establishment of early pulmonary inflammation with direct consequences on late evolution to fibrosis after lung injury. Their data 
Table 4 Stratification analyses between the genotypes of rs3748067 and CWP risk

\begin{tabular}{|c|c|c|c|c|c|c|c|}
\hline \multirow[t]{3}{*}{ Variables } & \multirow[t]{3}{*}{ Cases/controls } & \multicolumn{4}{|c|}{ Genotypes (cases/controls) } & \multirow[t]{3}{*}{$P^{a}$} & \multirow[t]{3}{*}{$\mathrm{OR}(95 \% \mathrm{Cl})^{\mathrm{a}}$} \\
\hline & & \multicolumn{2}{|l|}{$\mathrm{GG} / \mathrm{GA}$} & \multicolumn{2}{|l|}{ AA } & & \\
\hline & & $n$ & $\%$ & $n$ & $\%$ & & \\
\hline Total & $693 / 690$ & $679 / 659$ & $98.0 / 95.5$ & $14 / 31$ & $2.0 / 4.5$ & 0.014 & $0.44(0.23-0.85)$ \\
\hline \multicolumn{8}{|l|}{ Age } \\
\hline$<68$ & $276 / 405$ & $270 / 388$ & $97.8 / 95.8$ & $6 / 17$ & $2.2 / 4.2$ & 0.040 & $0.33(0.11-0.95)$ \\
\hline$\geq 68$ & $417 / 285$ & $409 / 271$ & $96.9 / 95.1$ & $8 / 14$ & $1.9 / 4.9$ & 0.041 & $0.68(0.16-0.96)$ \\
\hline \multicolumn{8}{|c|}{ Exposure years } \\
\hline$<27$ & $270 / 267$ & $264 / 255$ & $97.8 / 95.5$ & $6 / 12$ & $2.2 / 4.5$ & 0.210 & $0.52(0.19-1.44)$ \\
\hline$\geq 27$ & $423 / 423$ & $415 / 404$ & $95.5 / 98.1$ & $8 / 19$ & $1.9 / 4.5$ & 0.041 & $0.42(0.18-0.97)$ \\
\hline \multicolumn{8}{|c|}{ Smoking status } \\
\hline never & $340 / 359$ & $333 / 345$ & $98.0 / 96.1$ & $7 / 14$ & $2.1 / 3.9$ & 0.228 & $0.56(0.22-1.43)$ \\
\hline ever & $353 / 331$ & $346 / 214$ & $a m$ & $7 / 17$ & $2.0 / 5.1$ & 0.022 & $0.34(0.13-0.86)$ \\
\hline \multicolumn{8}{|l|}{ Stage } \\
\hline 1 & $415 / 690$ & $406 / 659$ & $97.8 / 95.5$ & $9 / 31$ & $2.2 / 4.5$ & 0.045 & $0.45(0.21-0.98)$ \\
\hline$\|$ & $217 / 690$ & $212 / 659$ & $97.7 / 95.5$ & $5 / 31$ & $2.3 / 4.5$ & 0.199 & $0.52(0.19-1.41)$ \\
\hline III & $61 / 690$ & $61 / 659$ & $100 / 95.5$ & $0 / 31$ & $0 / 4.5$ & & \\
\hline
\end{tabular}

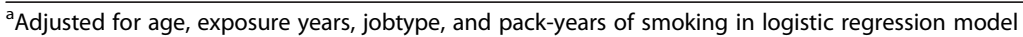

suggest that lung injury promotes IL-1 $\beta$ production which increases IL-23 expression and in turn can stimulate innate IL-17 expression [30]. Mark et al. [16] identified that genetic deletion of $I L-17 A$ significantly attenuated lung inflammation and fibrosis induced by BLM treatment. Second, $I L-17 A$ can stimulate collagen synthesis from fibroblasts, directly and/or indirectly, via fibroblast production of cytokines such as TGF- $\beta 1$ and connective growth factor (CTGF) [17]. IL-17A increased the synthesis and secretion of collagen and promoted the epithelial-mesenchymal transition in alveolar epithelial cells in a TGF- $\beta 1$ dependent manner [17]. Taiji et al. [31] reported that the $I L-17 A$ signaling pathway took an antifibrogenic effect in scleroderma fibroblasts as intrinsic activation of TGF- $\beta 1$ inhibits $I L$ $17 A$ signaling by the down-regulation of the receptor

Table 5 Stratification analyses between the genotypes of rs8193036 and CWP risk

\begin{tabular}{|c|c|c|c|c|c|c|c|}
\hline \multirow[t]{3}{*}{ Variables } & \multirow[t]{3}{*}{ Cases/controls } & \multicolumn{4}{|c|}{ Genotypes (cases/controls) } & \multirow[t]{3}{*}{$p^{a}$} & \multirow[t]{3}{*}{ OR $(95 \% C l)^{a}$} \\
\hline & & \multicolumn{2}{|l|}{$\overline{\mathrm{CC} / \mathrm{TC}}$} & \multicolumn{2}{|l|}{$\pi$} & & \\
\hline & & Number & Percent & Number & Percent & & \\
\hline Total & $693 / 690$ & $639 / 609$ & $92.2 / 88.3$ & $54 / 81$ & $7.8 / 11.7$ & 0.011 & $0.63(0.43-0.90)$ \\
\hline \multicolumn{8}{|l|}{ Age } \\
\hline$<68$ & $276 / 405$ & $258 / 354$ & $93.5 / 87.4$ & $18 / 51$ & $6.5 / 12.6$ & 0.025 & $0.50(0.27-0.92)$ \\
\hline$\geq 68$ & $417 / 285$ & $381 / 255$ & $91.4 / 89.5$ & $36 / 30$ & $8.63 / 10.5$ & 0.335 & $0.78(0.47-1.30)$ \\
\hline \multicolumn{8}{|c|}{ Exposure years } \\
\hline$<27$ & $270 / 267$ & $253 / 233$ & $93.7 / 82.3$ & $17 / 34$ & $6.3 / 12.7$ & 0.014 & $0.46(0.25-0.85)$ \\
\hline$\geq 27$ & $423 / 423$ & $386 / 376$ & $91.3 / 88.9$ & $37 / 47$ & $8.8 / 11.1$ & 0.227 & $0.75(0.48-1.19)$ \\
\hline \multicolumn{8}{|c|}{ Smoking status } \\
\hline never & $340 / 359$ & $309 / 319$ & $90.9 / 88.9$ & $31 / 40$ & $9.1 / 11.1$ & 0.448 & $0.82(0.50-1.36)$ \\
\hline ever & $353 / 331$ & $330 / 290$ & $93.5 / 87.6$ & $23 / 41$ & $6.5 / 12.4$ & 0.002 & $0.41(0.23-0.71)$ \\
\hline \multicolumn{8}{|l|}{ Stage } \\
\hline । & $415 / 690$ & $391 / 609$ & $94.2 / 88.3$ & $24 / 81$ & $5.8 / 11.7$ & 0.001 & $0.46(0.28-0.74)$ \\
\hline$\|$ & $217 / 690$ & $196 / 609$ & $90.3 / 88.3$ & $21 / 81$ & $9.7 / 11.7$ & 0.437 & $0.81(0.48-1.37)$ \\
\hline III & $61 / 690$ & $52 / 609$ & 85.3/88.3 & $9 / 81$ & 14.8/11.7 & 0.445 & $1.36(0.62-2.96)$ \\
\hline
\end{tabular}

${ }^{a}$ Adjusted for age, exposure years, and pack-years of smoking in logistic regression model 
Table 6 Interaction between IL-17A SNPs (rs3748067 and rs8193036) and smoking on CWP risk: case-control analysis

\begin{tabular}{llll}
\hline Interaction markers & $\beta$ & $\mathrm{OR}_{\mathrm{i}}(95 \% \mathrm{Cl})^{\mathrm{a}}$ & $P^{\mathrm{a}}$ \\
\hline rs3748067-smoking & -0.348 & $0.71(0.20-2.56)$ & 0.596 \\
rs8193036-smoking & -0.521 & $0.60(0.29-1.24)$ & 0.163 \\
\hline a Adjusted for age exposure years, and job type in logistic regression model
\end{tabular}

and contributed to the excess collagen accumulation and tissue fibrosis via miR-129-5p. Third, $I L-17 A$ could upregulate the expression of tissue inhibitor of metalloproteinase-1 (TIMP-1), and inhibited extracellular matrix (ECM) degradation by matrix metalloproteinases (MMPs) effectively [32].

To our knowledge, this is the first evaluation of the association between functional SNPs in $I L-17 A$ and CWP susceptibility in a Chinese population. Based on the above-mentioned studies, it seems that $I L-17 A$ may have a vital role in the pathogenesis and development of CWP. Investigation of $I L-17 A$ gene polymorphisms in patients with CWP and controls showed that the inheritance rate of rs3748067 AA genotype and rs8193036 TT genotype were more frequent in the controls than in the patients, thus they may be resistance factors for CWP. Furthermore, stratification analyses were applied, and each of these two SNPs (rs3748067 and rs8193036) significantly decreased CWP risk of individuals who has ever smoked.

Functional analyses of the 2 related $I L-17 A$ polymorphisms showed that rs8193036 $\mathrm{C}>\mathrm{T}$ influenced lower transcription of $I L-17 A$ in vitro. Rs3748067 was a locus of expression for interferon regulatory factor 4 (IRF4), a transcription factor that has been innumerable linked to the transient inflammation and progressive fibrosis [33]. Rs8193036 may be located on a transcription factor binding

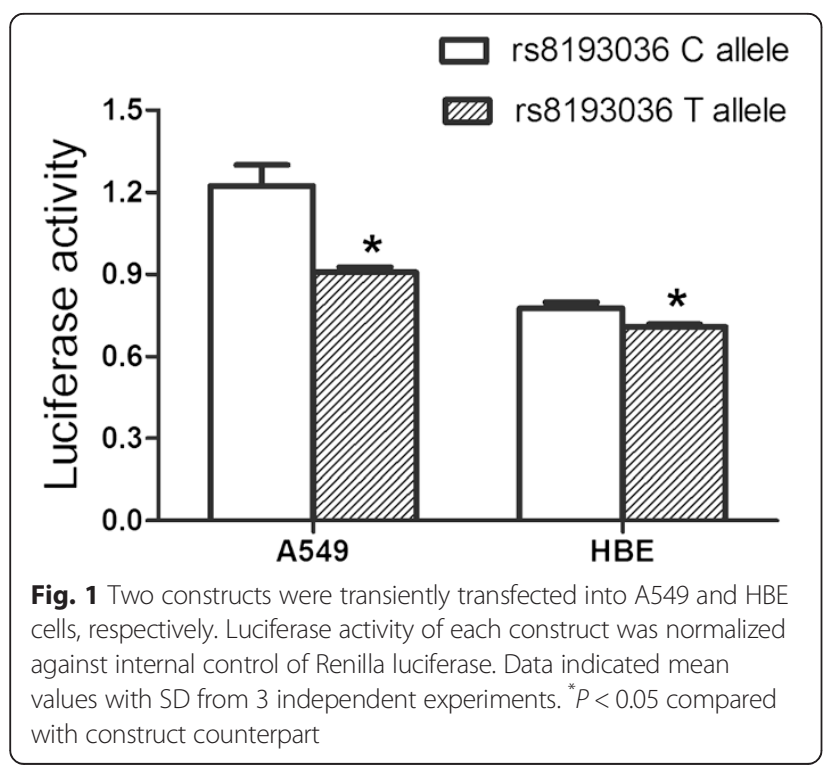

site (TFBS), affecting transcription activity and it may predispose individuals to fibrogenesis. These findings provide new insights into the role of $I L-17 A$ in the pathogenesis and development of CWP.

Several limitations of this present study should be considered. First, we matched the dust exposure levels by job titles and exposure years between case and control, and therefore, the selection bias could not be ruled out and the subjects could not fully represent the general populations of coal miners in China. Second, although our study suggested that rs3748067 and rs8193036 variations of $I L-17 A$ gene were associated with the risk of CWP, more biological background data and functional studies are needed to explain the results. Third, the sample size of this study is relatively moderate, which may reduce the statistical power to find the other difference between groups. Therefore, further large sample size studies with more diverse ethnic populations are required to replicate our results.

\section{Conclusion}

Taken together, the present study first indicates that two functional $I L-17 A$ SNPs (rs3748067 and rs8193036) are associated with decreased risk of CWP in a Chinese population, especially among the subgroup of smokers and patients with stage I. Further prospective study and strict case-control study are warranted to confirm our findings. Actually, the control of dust exposure in the workplace is the only way to totally eliminate pneumoconiosis.

\section{Abbreviations}

IL-17A: Interleukin 17A; CWP: Coal workers' pneumoconiosis; SNPs: Single nucleotide polymorphisms; COPD: Chronic obstructive pulmonary disease; BAL: Bronchoalveolar lavage; IPF: Idiopathic pulmonary fibrosis; HWE: Hardy-Weinberg equilibrium; ORs: Odds ratios; Cls: Confidence intervals; MAF: Minor allele frequency; BLM: Bleomycin; TGF- $\beta 1$ : Transforming growth factor- $\beta 1$; CTGF: connective growth factor; TIMP-1: Tissue inhibitor of metalloproteinase-1; ECM: Extracellular matrix degradation; MMPs: Matrix metalloproteinases; IRF4: Regulatory factor 4; TFBS: Transcription factor binding site.

\section{Competing interests}

The authors declare that they have no competing interests.

\section{Authors' contributions}

$\mathrm{RH}$ performed all of the laboratory studies under the supervision of $\mathrm{CN}$, analyzed the data and drafted the manuscript. XJ recruited and characterised patients with CWP for inclusion in the study. BW advised on A549 and HBE cell culture, reviewed the data, and revised the manuscript critically for intellectual content. TW, LH and JY reviewed the data, and revised the manuscript critically for intellectual content. BZ and CN conceived and designed the research, supervised $\mathrm{RH}$, analyzed the data, and drafted the manuscript. All authors approved the final manuscript.

\section{Acknowledgments}

This project carried out with the support of the National Science Foundation (No. 81273044). The work was also supported in part by Xuzhou Mining Business Group Co., Ltd.

\section{Author details}

${ }^{1}$ Department of Occupational Medicine and Environmental Health, School of Public Health, Nanjing Medical University, Nanjing 210029, China. ${ }^{2}$ Institute of 
Occupational Disease Prevention, Jiangsu Provincial Center for Disease Control and Prevention, Nanjing, China.

Received: 14 January 2015 Accepted: 20 July 2015

Published online: 30 July 2015

\section{References}

1. Centers for Disease Control and Prevention. Pneumoconiosis and advanced occupational lung disease among surface coal miners - 16 States, 2010-2011. MMWR Morb Mortal Wkly Rep. 2012;61(23):431-4.

2. McCunney RJ, Morfeld P, Payne S. What component of coal causes coal workers' pneumoconiosis? J Occup Environ Med. 2009;51(4):462-71.

3. Wynn TA. Fibrotic disease and the $T(H) 1 / T(H) 2$ paradigm. Nat Rev Immunol. 2004;4(8):583-94.

4. Ates I, Suzen HS, Yucesoy B, Tekin IO, Karakaya A. Association of cytokine gene polymorphisms in CWP and its severity in Turkish coal workers. Am J Ind Med. 2008;51(10):741-7.

5. Soutar CA. Dust concentrations and respiratory risks in coalminers: key risk estimates from the British Pneumoconiosis Field Research. Occup Environ Med. 2004;61(6):477-81.

6. Cohen RA. Is the increasing prevalence and severity of coal workers' pneumoconiosis in the United States due to increasing silica exposure? Occup Environ Med. 2010;67(10):649-50.

7. Weston A. Work-related lung diseases. IARC Sci Publ. 2011;163:387-405.

8. Brodlie M, McKean MC, Johnson GE, Anderson AE, Hilkens CM, Fisher AJ, et al. Raised interleukin-17 is immunolocalised to neutrophils in cystic fibrosis lung disease. Eur Respir J. 2011;37(6):1378-85.

9. Okamoto $Y$, Hasegawa M, Matsushita T, Hamaguchi Y, Huu DL, Iwakura Y, et al. Potential roles of interleukin-17A in the development of skin fibrosis in mice. Arthritis Rheum. 2012;64(11):3726-35.

10. Pridgeon C, Bugeon L, Donnelly L, Straschil U, Tudhope SJ, Fenwick P, et al. Regulation of IL-17 in chronic inflammation in the human lung. Clin Sci. 2011;120(12):515-24

11. Song LY, Weng D, Liu FW, Chen Y, Li CY, Dong L, et al. Tregs Promote the Differentiation of Th17 Cells in Silica-Induced Lung Fibrosis in Mice. PLoS One. 2012;7(5):e37286.

12. Aujla SJ, Dubin PJ, Kolls JK. Interleukin-17 in pulmonary host defense. Exp Lung Res. 2007;33(10):507-18.

13. Glader P, Smith ME, Malmhall C, Balder B, Sjostrand M, Qvarfordt I, et al. Interleukin-17-producing T-helper cells and related cytokines in human airways exposed to endotoxin. The European Respir J. 2010;36(5):1155-64.

14. Simonian PL, Roark CL, Born WK, O'Brien RL, Fontenot AP. $\gamma \delta T$ cells and Th17 cytokines in hypersensitivity pneumonitis and lung fibrosis. Transl Res. 2009:154(5):222-7.

15. Roark CL, Simonian PL, Fontenot AP, Born WK, O'Brien RL. gammadelta $T$ cells: an important source of IL-17. Curr Opin Immunol. 2008;20(3):353-7.

16. Wilson MS, Madala SK, Ramalingam TR, Gochuico BR, Rosas IO, Cheever AW, et al. Bleomycin and IL-1beta-mediated pulmonary fibrosis is IL-17A dependent. The J Exp Med. 2010;207(3):535-52.

17. Mi S, Li Z, Yang HZ, Liu H, Wang JP, Ma YG, et al. Blocking IL-17A promotes the resolution of pulmonary inflammation and fibrosis via TGF-beta1dependent and -independent mechanisms. J Immunol. 2011;187(6):3003-14.

18. Chen Y, Li C, Weng D, Song L, Tang W, Dai W, et al. Neutralization of interleukin-17A delays progression of silica-induced lung inflammation and fibrosis in C57BL/6 mice. Toxicol Appl Pharmacol. 2014;275(1):62-72.

19. Wang JY, Shyur SD, Wang WH, Liou YH, Lin CG, Wu YJ, et al. The polymorphisms of interleukin 17A (IL17A) gene and its association with pediatric asthma in Taiwanese population. Allergy. 2009;64(7):1056-60.

20. Wang S, Zhai H, Su Y, Wang Y. IL-17 F but not IL-17A gene polymorphism confers risk to multiple sclerosis in a Chinese Han population. J Neurol Sci. 2014;342(1-2):133-6.

21. Zhang $X$, Zheng $L$, Sun $Y$, Zhang $X$. Analysis of the association of interleukin-17 gene polymorphisms with gastric cancer risk and interaction with Helicobacter pylori infection in a Chinese population. Tumour Biol. 2014;35(2):1575-80.

22. Peng Y, Zhou B, Wang YY, Shi S, Zhang K, Zhang L, et al. Analysis of IL-17 gene polymorphisms in Chinese patients with dilated cardiomyopathy. Hum Immunol. 2013:74(5):635-9.

23. Wang $M, Y$, $Y$, Qian $H$, Song Z, Jia X, Zhang Z, et al. Common genetic variants in pre-microRNAs are associated with risk of coal. J Hum Genet. 2010;55(1):13-7.
24. Wang M, Wang S, Song Z, Ji X, Zhang Z, Zhou J, et al. Associations of IL-4, IL-4R, and IL-13 gene polymorphisms in coal workers' pneumoconiosis in China: a case-control study. PLoS One. 2011;6(8), e22624.

25. Kaminski N, Chen W, Liu Y, Wang H, Hnizdo E, Sun Y, et al. Long-Term Exposure to Silica Dust and Risk of Total and Cause-Specific Mortality in Chinese Workers: A Cohort Study. PLoS Med. 2012;9(4), e1001206.

26. Moran EM, Mastaglia FL. The role of interleukin-17 in immune-mediated inflammatory myopathies and possible therapeutic implications. Neuromuscul Disord. 2014;24(11):943-52.

27. Dong Z, Kang Q, Lei W, Zhong H, Tai W, Wang D. Effects of interleukin-17 on murine pulmonary fibroblast proliferation, transformation and collagen synthesis. Nan Fang Yi Ke Da Xue Xue Bao. 2012;32(1):75-9.

28. Tan HL, Regamey N, Brown S, Bush A, Lloyd CM, Davies JC. The Th17 pathway in cystic fibrosis lung disease. Am J Respir Crit Care Med. 2011;184(2):252-8.

29. Meng F, Wang K, Aoyama T, Grivennikov SI, Paik Y, Scholten D, et al. Interleukin-17 signaling in inflammatory, Kupffer cells, and hepatic stellate cells exacerbates liver fibrosis in mice. Gastroenterology. 2012;143(3):765-76. e761-763.

30. Gasse P, Riteau N, Vacher R, Michel ML, Fautrel A, di Padova F, et al. IL-1 and IL-23 mediate early IL-17A production in pulmonary inflammation leading to late fibrosis. PLoS One. 2011;6(8), e23185.

31. Nakashima T, Jinnin M, Yamane K, Honda N, Kajihara I, Makino T, et al. Impaired IL-17 signaling pathway contributes to the increased collagen expression in scleroderma fibroblasts. J Immunol. 2012;188(8):3573-83.

32. Biancheri P, Pender SL, Ammoscato F, Giuffrida P, Sampietro G, Ardizzone S, et al. The role of interleukin 17 in Crohn's disease-associated intestinal fibrosis. Fibrogenesis \& Tissue Repair. 2013;6(1):13.

33. Gunthner R, Kumar VR, Lorenz G, Anders HJ, Lech M. Pattern-recognition receptor signaling regulator mRNA expression in humans and mice, and in transient inflammation or progressive fibrosis. Int J Mol Sci. 2013;14(9):18124-47.

\section{Submit your next manuscript to BioMed Central and take full advantage of:}

- Convenient online submission

- Thorough peer review

- No space constraints or color figure charges

- Immediate publication on acceptance

- Inclusion in PubMed, CAS, Scopus and Google Scholar

- Research which is freely available for redistribution

Submit your manuscript at www.biomedcentral.com/submit
C) Biomed Central 